\title{
SOCIABILIDADES, TRABALHO SEXUAL E AUTONOMIA NO CONTEXTO DAS GRANDES OBRAS NA AMAZÔNIA BRASILEIRA
}

\author{
SOCIABILITIES, SEXUAL WORK AND AUTONOMY IN THE CONTEXT \\ OF THE GREAT WORKS IN THE BRAZILIAN AMAZON
}

\author{
W. R. M. ARAÚJO1,* \\ ${ }^{1}$ Universidade Federal do Rio Grande do Sul, Programa de Pós Graduação e, Sociologia, Brasil.
}

\author{
ART I C LE INFO \\ Article history: \\ Received 2018-08-05 \\ Accepted 2018-10-16 \\ Available online 2018-10-31 \\ *Autor correspondente: \\ E-mail:marquesreis@hotmail.com
}

Palavras-chave: Autonomia. Sociabilidade. Trabalho sexual. Gênero. Amazônia brasileira.

Keywords: Autonomy. Sociability. Sex work. Gender. Brazilian Amazon.

RESUMO. Neste texto apresento alguns dados parciais e reflexões teóricas referentes ao trabalho de campo que foi realizado durante os meses de junho de 2014 e novembro de 2015. Os dados foram coletados por meio de entrevistas em profundidade aplicadas a doze prostitutas em um contexto privilegiado pela observação direta e, também, pela abordagem etnográfica que foi realizada nos locais de trabalho das mulheres. Objetivando preservar a identidade das entrevistadas, adoto nomes de flores para identificá-las neste texto. Na modalidade de trabalho sexual exercida nos bares de prostituição do contexto pesquisado, as prostitutas declararam ter encontrado na prostituição possibilidades de negociações e de ganhos econômicos inexistentes no mercado de trabalho formal. Por exemplo, flexibilidade em termos de jornadas de trabalho, possibilidades de ganhos econômicos (principalmente entre as mais jovens) e mobilidade social impossíveis de se alcançarem através de outras atividades profissionais relegadas às mulheres dos estratos sociais subalternizados do Brasil. A amostra analisada não corresponde ao número total de trabalhadoras sexuais entrevistadas na consecução da pesquisa de campo do doutorado em Sociologia, pela Universidade Federal do Rio Grande do Sul (UFRGS). Priorizei aqui a compreensão e, sobretudo, a visão que as entrevistadas compartilham em relação à referida atividade ser profissional, embora não seja regulamentada e apesar de não haver, no município de Porto Velho, mobilização de trabalhadoras sexuais em torno de coletivos políticos, as mulheres têm esse entendimento. Pode-se concluir que, em suas práticas, as trabalhadoras sexuais estabelecem relações personalistas (com seus clientes e dono/as de estabelecimentos) onde parece haver margens seguras para a oferta de serviços de natureza sexual e negociação de seus agenciamentos corporais.

ABSTRACT. In this text I present some partial data and theoretical reflections regarding the field work that was carried out during the months of June 2014 and November 2015. The data were collected through indepth interviews applied to twelve prostitutes in a context privileged by direct observation and also by the 
ethnographic approach that was carried out in women's workplaces. In order to preserve the identity of the interviewees, I adopt names of flowers to identify them in this text. In the form of sex work practiced in bars of prostitution in the context studied, prostitutes declared that they had found in prostitution possibilities for negotiations and economic gains that did not exist in the formal labor market. For example, flexibility in terms of working hours, possibilities of economic gains (especially among the younger ones) and social mobility that cannot be achieved through other professional activities relegated to women of the subalternized social strata of Brazil. The sample analyzed does not correspond to the total number of sex workers interviewed in the field research of the PhD in Sociology, by the Federal University of Rio Grande do Sul (UFRGS). I prioritized here the understanding and, above all, the view that the interviewees share in relation to the said activity to be professional, although it is not regulated and although in the municipality of Porto Velho there is no mobilization of sex workers around political groups, women have this understanding. It can be concluded that in their practices, sex workers establish personal relationships (with their clients and owners of establishments) where there seems to be safe margins for the offer of services of a sexual nature and negotiation of their agency.

\section{Introdução}

A zona mantém todas as suas funções clássicas, mas parece perder seu caráter contingente. O passar do tempo ali já não ecoa irreversível

(SIMÕES, 2010, p. 13).

Inicialmente cabe pontuar que esta abordagem parte da perspectiva de Silva e Blanchette (2011) que buscam compreender a prostituição feminina dentro da situação macroeconômica da mulher urbana no Brasil. No entendimento deles, "a prostituição heterossexual de mulheres é uma forma de trabalho com grandes articulações ao gênero e, portanto, só faz sentido em termos econômicos quando é situada frente à situação de trabalho feminizado em geral" (SILVA e BLANCHETTE, 2011, p. 8). Na fase de implantação dos canteiros de obras das Usinas Hidrelétricas (UHEs) Santo Antonio e Jirau, construídas no estado de Rondônia, ocorreu uma proliferação de bares de prostituição (conhecidos localmente como bregas) motivada pelo aumento da presença de milhares de trabalhadores predominantemente do sexo masculino em Porto Velho, capital do Estado.

Durante o trabalho de campo pude verificar uma presença significativa de mulheres em situação de prostituição, muitas delas de diferentes localidades geográficas (inclusive da Bolívia e Venezuela), deslocando-se com certa frequência em busca de lugares com maiores possibilidades de clientela. Muitas delas, porém, retornando periodicamente a seus locais de origem para visitar familiares (muitas vezes levando quantias de dinheiro acumulado durante as temporadas de trabalho sexual). À vista desse contexto as questões norteadoras da pesquisa forma repensadas, com base no que os dados empíricos apontaram.

Naquele período pode-se perceber a instalação de inúmeros estabelecimentos vinculados à oferta de sexo comercial como bares, boates, bordéis, drinks, entre outros. 
Entretanto, os bregas que são bares de prostituição ganharam notoriedade na área portuária de Porto Velho e em Jaci Paraná, um distrito dessa capital localizado próximo à UHE Jirau, pela concentração de estabelecimentos, perfil dos frequentadores e modalidade de prostituição praticada.

\section{Os bares de prostituição}

O estigma da puta não tem tanto a ver com algumas mulheres cobrarem por sexo. Na métrica machista, "puta" é toda aquela que não se submete, seja ela presidente, mulher em cargo de chefia, prostituta ou mulher de vida sexual ativa. Mas a ofensa sempre recai sobre a sexualidade, pois é considerada a pior ofensa para todas as mulheres (Monique Prada, ativista da prostituição, 2017).

O início da implantação de uma frente de trabalho nos canteiros de obras das UHEs Jirau e Santo Antonio entre os anos de 2008 e 2010, constituída por uma massa de trabalhadores homens, atraiu mulheres de diferentes origens sociais e com diversificados níveis de escolaridade e de procedências. Na proporção em que os canteiros de obras foram se ampliando e a quantidade de operários crescia, viu-se aumentar significativamente a presença de profissionais do sexo nas áreas de prostituição da capital rondoniense e em localidades próximas.

A presença de milhares de trabalhadores homens fomentou a implantação de dezenas de estabelecimentos comerciais, estruturados de forma precária e informal, destinados ao entretenimento dos operários das UHEs. Um número incalculável de mulheres se deslocava até Porto Velho e Jaci Paraná fretando ônibus especiais (no caso das acreanas) ou por meio de transporte aéreo. Tais deslocamentos tinham como destino os bares e boates de prostituição ocorrendo, especialmente, durante o período de maior circulação de dinheiro que era durante o período de pagamento de salários dos trabalhadores das obras de construção das hidrelétricas.

Em Jaci Paraná, por exemplo, foram mapeados em junho de 2011 aproximadamente 44 bregas1, construídos em casas feitas de tábuas de madeira e telhas de fibra, que funcionavam diariamente, por vinte e quatros horas, para corresponder à demanda de entretenimento de uma parcela dos 35 mil trabalhadores homens das duas obras juntas. Nos fins do ano de 2015, com a fase final de conclusão das hidrelétricas, pude constatar que a presença de trabalhadores diminuiu significativamente. Isso incidiu diretamente nos números de estabelecimentos vinculados à prostituição, porém o distrito de Jaci Paraná

\footnotetext{
${ }^{1}$ Estes dados foram retirados da matéria "Terra sem lei: prostituição, drogas e violência na maior obra do PAC", publicada pela Revista Marie Claire de junho de 2011, que traz os resultados de uma reportagem investigativa da jornalista Maria Laura Neves, onde aponta os problemas sociais decorrente da construção das UHEs que atraiu milhares de migrantes para o distrito de Jaci Paraná.
} 
ainda se caracterizava como um polo dormitório e de entretenimento para os operários das obras de construção da hidrelétrica de Jirau.

Em Porto Velho, comumente os bregas estão localizados nas áreas próximas às obras de infraestrutura hidrelétrica e rodoviária e, especialmente, nas adjacências da região portuária e garimpeira (bares flutuantes) do rio Madeira onde há um grande fluxo diário de homens. Tais lugares são procurados por grupos assíduos de operários das obras das UHEs e, também, por homens das classes populares locais, cujo principal objetivo seria de suprir as lacunas de sociabilidades do contexto dos canteiros de obras e de locais de grandes concentrações masculinas.

No contexto das grandes obras da Amazônia brasileira, tais estabelecimentos funcionam também como um mecanismo informal de controle das tensões sociais dos operários das hidrelétricas. Assim como exercem uma função relevante como espaço para a prática de rituais de masculinidades entre homens de classes populares (beber, fumar, jogar, iniciar a vida sexual, envolver-se em jogatinas, "conversar coisas de homens" e contratar programas das prostitutas).

Os clientes são construídos, em geral, a partir da perspectiva dos vínculos estabelecidos nos locais de trabalho dos homens - especialmente quando se trata de operários das UHEs e de trabalhadores do porto hidroviário de Porto Velho - que são estreitados nos bares de prostituição onde se encontram diariamente após os turnos de trabalho. Frequentemente, eles vão aos bares em grupo objetivando compartilhar momentos de entretenimento com os amigos nos finais de semana e, especialmente no final das jornadas de trabalho durante os períodos de pagamento de salários, ocasiões nas quais ostentam sobre as mesas garrafas de uísques, bebidas energéticas, entre outros símbolos de status.

Os operários têm presença assídua nos bregas onde transpõem os limites das relações estritamente comerciais com as mulheres e donos (muitos deles ex-prostitutas) dos estabelecimentos, alcançando a posição de "amigos da casa" ou "amigos das meninas". Independentemente da intenção do cliente, ele receberá inicialmente toda a atenção da prostituta que entre as suas atribuições profissionais consta, também, fazer com ele gaste o máximo possível com o consumo de bebidas e porções de "tira-gosto", fichas da máquina de música e partidas de bilhar (sinuca). Considerando que ela receberá comissão sobre o consumo de seu acompanhante e, segundo relataram, os lucros do estabelecimento consistem exclusivamente na venda de bebidas alcoólicas e aluguéis dos quartos para encontros íntimos.

Nestes estabelecimentos, nem sempre o contrato dos serviços sexuais é estabelecido, considerando que muitos homens procuram os estabelecimentos 
exclusivamente para conversar, beber e jogar sinuca, a prostituta é gratificada financeiramente ou com presentes por seu acompanhante.

Desse modo, são estabelecidas redes de relações sociais onde os homens buscam, por um lado, companhia feminina para conversar, consumir bebidas alcoólicas, dançar, escutar música e jogar sinuca; assim, entre outras formas de sociabilidades, eles buscam por relacionamentos afetivos e contratos sexuais com as prostitutas. Por outro, os bregas aparecem como um lugar importante para as mulheres que se inserem na prostituição, onde estabelecem com seus proprietários relações de trabalho informal que parecem estar permeadas por laços de afinidades, reciprocidades e sociabilidades.

$\mathrm{Na}$ interação com os frequentadores desses lugares, elas vislumbram a negociação de programas, possibilidades de arranjos afetivo-sexuais duradouros e gratificações pela companhia e presentes. Conforme ilustra o depoimento de uma entrevistada:

No domingo vêm muitos, são barrageiros. Eles vêm para beber, brincam e gostam da gente. Mas nenhum fica com a gente. Têm muitos que dá vinte [reais], dá trinta [reais], cinquenta... Assim, nós ficamos bebendo, brincando, mas têm muitos que não dão nada. Mas nós não nos importamos, não levamos em conta. Nós já conhecemos, ficamos ali bebendo, pois a maioria é amizade (Entrevista, Gardênia, novembro de 2015).

Em termos de autonomia econômica, as trabalhadoras sexuais confirmam a importância desses estabelecimentos como local de trabalho que lhes garantiu a consecução de projetos pessoais. Por exemplo, a casa própria, melhores condições de vida para os filhos/as, pequenos comércios, compras veículos automotores, a maioria motocicletas, especialmente nos período em que havia uma maior circulação de clientes que foi na fase de implantação dos canteiros de obras das hidrelétricas.

Embora a necessidade econômica apareça, por um lado, como a principal motivação para a inserção na atividade prostitucional. Por outro, as motivações parecem remeter menos para questões macroestruturais do que para elementos que perpassam as trajetórias pessoais das mulheres, especialmente os que dizem respeito às questões de gênero e à suas sexualidades os quais têm a ver com a autonomia pessoal. Nesse caso:

O corpo da mulher na prostituição é usado por ela mesma como um instrumento para seduzir, fazer sexo, fazer companhia ou simplesmente conversar com homens com o explícito propósito de ganhar dinheiro. E a compra dos bens vendidos por ela é feita voluntariamente pelos homens interessados, sem nenhuma espécie de coação (COLVERO, 2010, p. 18).

No contexto pesquisado, as trabalhadoras sexuais rompem com os papéis tradicionais de gênero ultrapassando barreiras no uso do corpo como, por exemplo, o sexo relacionado à monogamia, à reprodução e à conjugalidade. Desse modo, a necessidade econômica aparece como uma autojustificativa comum entre as prostitutas com origem nos 
estratos sociais populares, pois essa seria a única condição que justificaria a inserção no trabalho sexual.

Nesse sentido, os dados coligidos permitem apontar como motivação possível a possibilidade de conciliar o trabalho sexual com outras atividades como, por exemplo, a venda de produtos de beleza e o trabalho de diarista que não garantem ganhos seguros (e também os cuidados com a casa e filhos). As entrevistas apontam, de fato, como motivação principal pela permanência na prostituição a flexibilidade de horários de trabalho sexual e a possibilidade de conseguir clientes fixos que resultem numa atividade com ganhos e gratificações impossíveis de se alcançar em atividades formais relegadas às mulheres desses estratos sociais.

\section{As sociabilidades nos bregas de Porto Velho}

A prostituta não é um corpo que goza, se comove, ri, chora, se dilacera, se extasia, sofre; é um corpo que trabalha, que representa uma personagem particular numa peça particular escrita pelos clientes, é o corpo que encarna o teatro íntimo de um estranho e, por isso, será chamado a fazer calarem-se nele seus caprichos e suas vontades (BRUCKNER e FINKIELKRAUT, 1981, p. 85).

Os bregas iniciam as suas atividades a partir das 9 horas da manhã permanecendo, quase sempre, abertos diariamente ou enquanto houver clientes consumindo. Apesar disso, conforme relatou a proprietária de um desses estabelecimentos, o horário de funcionamento dos bares/bregas encerra-se frequentemente por volta das 22 horas por questões de segurança. Nesses estabelecimentos não são oferecidos serviços sexuais sofisticados massagens especiais, pole dance, strip-tease, shows eróticos, etc. - pois, sem exceção, dispõem de estruturas físicas bastante simples.

De um lado, trata-se de locais públicos para entretenimento masculino sem elementos visuais que indiquem as suas vinculações com o mercado do sexo, de outro, são estabelecimentos geralmente associados quase que exclusivamente com a prostituição. Em geral, os estabelecimentos funcionam em locais bem precários e de forma irregular, dispondo de uma estrutura física que comporta pouco mais do que alguns jogos de mesa com quatro cadeiras, máquina de música junkbox e mesa para jogo de bilhar. Muitos dos bregas dispõem, eles próprios, de quartos que são alugados para os clientes por $R \$ 30,00$ (trinta reais) a chave para os encontros íntimos contratados de alguma "garota" vinculada ao estabelecimento.Tudo isso, garante o movimento diário de frequentadores, principalmente, durante os fins de semana e períodos de pagamentos de salários dos trabalhadores das usinas, desde que o local seja frequentado por mulheres que estejam dispostas a interagir com os homens que frequentam esses locais. 
Mas o que, de fato, faz com que o bar/brega seja "bem frequentado" por uma clientela disposta a gastar com bebidas, gratificações e/ou programas, é o grande prestígio2 do qual gozam alguns proprietários/as, tanto entre os frequentadores como entre as mulheres que buscam esses estabelecimentos para o exercício da prostituição. Tal prestígio é conquistado através do atendimento personalizado dispensado aos "clientes especiais" que, em alguma medida, tornam-se "amigos da casa" ou, seja um cliente habitué dos serviços do lugar que, em geral, envolve alguma forma de camaradagem e dádivas entre os agentes envolvidos, por exemplo, ser chamado por apelidos carinhosos, cortesias, sentar-se à mesa do cliente e compartilhar da sua bebida, conciliar conflitos entre clientes e entres esses e garotas, indicar garotas, vender a crédito, etc..

A figura desses agenciadores, percebidos como empreenderes/as de estabelecimentos comerciais vinculados ao mercado do sexo local, traz evidências que possibilitam romper com as representações clássicas do cafetão e da cafetina associadas exclusivamente à exploração do trabalho da prostituta. Algumas abordagens, como as de Olivar (2013) e Tedesco (2008), realizaram estudos da prostituição a partir de perspectiva focada nas questões de identidade e do estigma de profissionais do sexo, trazendo elementos que rompem, definitivamente, com as representações clássicas da figura do cafetão e da cafetina. Meu campo de pesquisa raríssimas vezes se ajustou a ideia da subalternização das mulheres que se prostituem por parte desses agentes.

Tedesco (2008) ao analisar as relações comerciais e afetivas entre mulheres que se prostituem e os demais agentes da prostituição, constata que os termos cafetão e gigolô (permeado por noções estigmatizadas) são utilizados de forma ambígua e confusa tanto pelas prostitutas como pelos demais agentes da prostituição e que, as relações entre as prostitutas e esses agentes caracterizam-se, muitas vezes, por relações imbricadas em afetos, pois muitos desses homens, ao contrário de explorá-las, "exercem vários papéis em uma parceria mútua que envolve o mundo do trabalho e dos afetos".

Já o estudo de Araújo, seguindo outra perspectiva de análise, indica que a figura clássica da cafetina ou cafetão tem desaparecido fato que, conforme constata o autor, devese a atual diversificação e ampliação das modalidades de serviços sexuais, como "a praticada nas ruas, bares e boates, além dos anúncios de jornais e sites da internet que são utilizados para o oferecimento dos serviços dos profissionais do sexo" (ARAUJO, 2006, p. 98).

Nesse particular, pude observar que nos bares/bregas cujas proprietárias foram prostitutas durante anos (ou que conciliam as duas atividades) acumulando, portanto, uma

\footnotetext{
${ }^{2}$ Como observa Gaspar (1985), partindo de um contexto mais amplo de análise: "Do ponto de vista do cliente, o prestígio desses agenciadores [cafetões e cafetinas] liga-se à sua capacidade de oferecer mulheres que satisfaçam a qualquer hora as suas exigências (beleza e performance sexual). Do ponto de vista das prostitutas, à sua oferta de programas bem remunerados" (GASPAR,1985, p. 21).
} 
bagagem de conhecimento prático que elas acionam - em termos de administração dos seus negócios e das relações interpessoais entre os diferentes agentes da prostituição -, há uma noção de "cuidado" em relação aos clientes de seus estabelecimentos. Na fala de uma de nossas informantes (dona de bar/brega), aparece claramente o "cuidado" que ela dedica a seus clientes: "aqui todo mundo é família, eu cuido dos meninos quando eles bebem muito, pois tem muita gente ruim que aproveita da situação pra brigar, roubar, fazer mal".

$\mathrm{Na}$ prática essas noções de "cuidado" são demonstradas em contextos nos quais o "bom cliente" bebe "além da conta" e, em alguma medida, fica mais suscetível a envolver-se em brigas e confusões. Tal situação acontece com bastante frequência, com os trabalhadores das hidrelétricas vindos de outras regiões do país que, por descuido e desconhecimento da região, fazem amizades com "noiados" (dependentes de drogas ilícitas) e "malandros" (indivíduos envolvidos em pequenos delitos), conforme foi relatado por mais de uma entrevistada.

Eles ficam embriagados, eu falava: - Olha cuidado fulano, beltrano, olha! Eu ficava cuidando deles, porque eu já sabia os que eram más influências e os que não eram. Porque eu já tenho quinze anos nesta região e já conheço um pouco as pessoas que ficam arrodeando. Então eu falava: - "Não se acompanhe com esse, porque não dá certo. É uma pessoa que... é usuário pode te vender, te assaltar ou roubar". Eu os avisava (Entrevista, Amarílis, novembro de 2015).

Nessas situações, como presenciamos durante a observação etnográfica, a proprietária do estabelecimento entra em cena na condição de conselheiro/amigo, intervindo diretamente nos conflitos e brigas em favor do "bom cliente", ou ainda, guardando seus "pertences de valor" (aparelho de celular, carteira, chaves de veículos, etc.).

\section{A autonomia da prostituta}

Na prostituição, aprendi a ver que a sociedade tem muitos problemas e eu não era a errada da história (Lourdes Barreto, 76 anos, Putafeminista e coordenadora do Gempac, 2012).

A região do Terminal Hidroviário Cai N'água apresenta características bem distintas de outras áreas de prostituição de Porto Velho no tocante à presença e fluxo de prostitutas. Em geral, são mulheres da própria cidade migrantes do interior do estado que têm uma origem social nos estratos subalternizados, cujas presenças são percebidas nos bares/bregas a partir das primeiras horas da manhã. A presença de mulheres nos bares/bregas é mais intensa nos turnos vespertino e noturno que funcionam como turnos de trabalho mais ou menos flexíveis, conforme frequência de clientes nos estabelecimentos. 
Em seus depoimentos, as trabalhadoras sexuais revelam que a condição prostitucional é ocultada dos familiares e pessoas próximas, porém elas mantêm relações estreitas com familiares próximos diferentemente de mulheres que estão em "trânsito" por áreas de prostituição "sazonal", que disseram ter rompido os laços familiares - para ocultar uma identidade deteriorada enquanto um estigma, nos moldes da análise de Goffman (2008) -, restituindo-os apenas quando alcança uma posição econômica favorável ${ }^{3}$.

Diferente de outros contextos da pesquisa em andamento, algumas mulheres acumulam (paralelamente) o trabalho sexual com a função de garçonete/cozinheira, o que as diferencia das demais prostitutas. Elas mantêm um vínculo informal de trabalho com os donos dos estabelecimentos cumprindo horários fixos de trabalho (com certa flexibilidade), porém sem quem haja a fixação de um contrato formal de trabalho como comerciárias.

Tal aspecto parece indicar que uma parcela significativa das mulheres com múltiplas funções, que se prostituem em bares de prostituição da região portuária dessa capital, são exploradas em termos laborais por não terem a sua situação de trabalho regulamentada por seus empregadores. Mas geralmente essas profissionais estão inseridas dentro de redes femininas de cuidados e solidariedade (e às vezes de proteção), principalmente quando o proprietário do estabelecimento é uma ex-prostituta.

Durante o campo pude constatar, por mais de uma vez e em diferentes lugares, como são constituídas essas redes de cuidados e solidariedades entre donas de bregas e suas funcionárias (garçonetes/cozinheiras). Por exemplo, a prostituta veterana que convida a amiga para juntas abrirem o próprio empreendimento; a prostituta que acumula as funções de cozinheira e balconista que convida a proprietário estabelecimento em que trabalha para ser a madrinha de seu filho, nascido de uma gestação planejada; entre outras situações presenciadas por nós.

$\mathrm{Na}$ realidade, aquelas que se encontram em tal posição realizam uma série de atividades: atendem o balcão, servem os clientes, realizam serviços de limpeza, preparam porções de "tira-gostos" e, opcionalmente, prestam serviços sexuais, bem como são responsáveis pelo estabelecimento na ausência do/a dono/a.

Não temos horário fixo de trabalho. Quem determina o meu horário de trabalho sou eu. Eu defino o meu horário! Mas tenho a minha obrigação de chegar cedo. A partir do momento que eu fiz a minha obrigação, se não tem movimento eu vou direto para casa. Quando ela [dona do estabelecimento] pode me pagar por dia, ela paga. Quando ela pode pagar por semana, ela paga e assim vai (Entrevista, Violeta, novembro de 2015).

\footnotetext{
${ }^{3}$ Nas entrevistas realizadas no distrito de Jaci-Paraná foi possível constatar um maior número de profissionais de outras regiões brasileiras (pelo fato desse distrito a continua sendo um ponto de atração interessante para elas), principalmente dos estados do Acre, Mato Grosso e também da Bolívia, cujas trajetórias no trabalho sexual são marcadas por rompimentos com seus locais de origem e laços familiares.
} 
Tais mulheres exercem dupla função (ou mesmo tripla), o que faz com que elas estabeleçam vínculos informais com seus empregadores, cumprindo diariamente horários fixos de trabalho paralelo à prostituição. Lembre-se que os artigos do Código Penal brasileiro criminalizam o favorecimento da prostituição (art. 228), a exploração de casa de prostituição (art. 229), tirar proveito da prostituição alheia (art. 230), o de promover ou facilitar a entrada, em território nacional, de pessoas com a finalidade de prostituição (art. 231) e o de promover ou facilitar de deslocamento de alguém do território nacional para prostituição (art. 231-A).

As indefinições conceituais ${ }^{4}$ presentes na redação desses artigos (particularmente no âmbito das relações entre o Estado, as feministas de orientação abolicionista e sociedade civil conservadora), têm sido há bastante tempo alvo de críticas de segmentos feministas envolvidos na defesa e promoção dos direitos das/os profissionais do sexo brasileiros que são unânimes ao apontar duas problemáticas: (i) a equiparação da prostituição voluntária de indivíduos maiores de dezoito anos à exploração sexual infantil e (ii) a vinculação entre prostituição, exploração sexual e tráfico de mulheres ${ }^{5}$.

Nessa direção, deve-se atentar que a situação de informalidade dos profissionais do sexo como um todo, trata-se, em geral, de uma estratégia adotada pelos/as proprietários de estabelecimentos vinculados à prostituição. Considerando que a legislação brasileira criminaliza as relações de trabalho no universo da prostituição, mas não o trabalho autônomo da prostituta.

A falta de regulamentação das atividades dos/as profissionais do sexo podem submetê-los a condições degradantes de trabalho. Considera-se que a não percepção da prostituição como trabalho, em uma sociedade cuja condição de trabalhador é o que determina a valorização do sujeito, é uma forma de desvalorização das prostitutas (KEMPADOO, 2005) que contribui para o aumento da sua vulnerabilidade e estigma (JULIANO, 2005).

Nesse sentido, os bares/bregas da região portuária dispõem sempre de um número regular de mulheres (geralmente jovens) com vínculos exclusivos, cuja fidelização é garantida graças a incentivos donos/as estabelecimentos, que concedem "algumas gentilezas para a garota": disponibilizam bebidas, cigarros, alimentação e clientes rentáveis.

\footnotetext{
${ }^{4} \mathrm{Na}$ redação atual onde se lê: "Art. 228. Induzir ou atrair alguém à prostituição ou outra forma de exploração sexual, facilitá-la, impedir ou dificultar que alguém a abandone:" "Art. 231. Promover ou facilitar a entrada, no território nacional, de alguém que nele venha a exercer a prostituição ou outra forma de exploração sexual, ou a saída de alguém que vá exercê-la no estrangeiro" (Grifos nossos), a prostituição voluntária é equiparada a exploração sexual (prostituição forçada) quando a tipifica como uma forma de exploração, o é uso da conjunção OU que dá sentido aos referidos artigos do Código Penal. (Grifos

${ }^{5}$ Em texto bastante vigoroso, publicado em 2013 no livro "Desafios da Antropologia Brasileira", organizado por Bela FeldanBianco, essa antropóloga feminista envolvida há décadas em pesquisas acerca da indústria transnacional do sexo e do tráfico de mulheres, traz contribuições bastante significativas sobre a problemática apontado a tensão gerada em torno da prostituição e do "tráfico de mulheres".
} 
Muitas delas relataram que são "livres" para organizar a sua própria jornada de trabalho em termos de dias e horários, além de poderem trabalhar quando (e onde) bem quiserem.

Eu fui porque eu quis mesmo. Lá é uma boate... Um brega! Não tenho nenhum horário de trabalho ali não. De jeito nenhum! Se eu decidir não ir lá, não vou. Ela não tem nada a ver com a minha vida. Entrei lá na tora [começou a trabalhar no local] e saio. Entro e saio, a porta é aberta. Até à noite todo mundo sai fora (Entrevista, Rosa, novembro de 2015).

$\mathrm{Na}$ prática não acontece dessa forma, há marcadores sociais de diferença que interferem na autonomia profissional dessas mulheres. Tal liberdade está, de fato, bem mais relacionada às mulheres de "certa idade" (ou que não representam um ideal estético de beleza desejado pelos clientes) do que as mulheres jovens, que precisam manter uma rotina diária de trabalho vinculada a determinado estabelecimento. Isto é, o fator etário é um marcador social de diferença atua diretamente no agenciamento das prostitutas jovens.

No contexto pesquisado, os bares de prostituição diferentemente das boates fechadas proporcionam, conforme os depoimentos das entrevistadas, vantagens em termos de negociação dos valores dos programas e da não cobrança de diárias pelos proprietários dos estabelecimentos, bem como a flexibilidade em temos de horários e locais de trabalho. Tais aspectos indicam certo grau de autonomia das prostitutas conforme indicam os depoimentos de diferente informantes:

\begin{abstract}
Eu não tenho local fixo de trabalho. Até porque, hoje, é a terceira vez que eu venho aqui. Eu não fico aqui! Eu não gosto de me expor! Não gosto de ir à boates. Fui uns três meses só que não vale a pena. Porque lá os donos querem que a gente beba uísque e red boll para dar lucro para a casa. Aqui, não sou obrigada a beber. Eu não gosto de beber. Eu não bebo e não fumo. $\mathrm{Ai}$, eu não quis, não fui mais. [...] Aqui, não tem horário fixo. Se a pessoa ligar aqui para mim e diz: - "Jéssica [nome profissional], você está desocupada agora?" Se eu estiver a gente encontra. Se não, eu não vou. Se eu não quiser, também não vou (Entrevista, Amarílis, novembro de 2015).
\end{abstract}

Embora as trabalhadoras sexuais dos bares de prostituição não sejam obrigadas a consumir bebidas alcoólicas (apesar de muitas delas beberem com os clientes), elas são incentivadas a fazer com que os homens os quais fazem companhia gastem com bebidas alcoólicas, jogos de sinuca e fichas nas máquinas junkbox. Além das possíveis gratificações pela companhia (caso o cliente não contrate os serviços sexuais), a trabalhadora sexual recebe um percentual sobre cada cerveja ou bebida que o seu acompanhante consumir sendo. Nessas ocasiões, ela recebe uma pulseira de látex colorida para cada bebida consumida pelo cliente, cujas cores são um indicativo do percentual que a mulher receberá por cada cerveja e/ou drink consumidos por seus acompanhantes.

No entanto, caso o cliente contrate os serviços sexuais da prostituta cabe a esse efetuar o pagamento antecipado do programa e da "chave" (aluguel do quarto) ao dono/a do 
bar. Do montante pago, conforme elas relataram nas entrevistas, apenas o valor do aluguel do quarto é retido pelo/a proprietário bar, ou seja, o valor do programa é entregue integralmente à trabalhadora sexual no final do expediente ou semanalmente, variando conforme a relação da prostituta com o estabelecimento.

Ele paga para a dona, só que antes de ir para o quarto ele dá o dinheiro do meu programa que é $R \$ 150,00$ e $R \$ 30,00$ que é das chaves. Eu não pago nada para ela [proprietária]. Aqui eu não tenho que beber! Mas nas outras boates tipo Bataclan, Enigma e Baco... Na Bacco nem tanto! Mas nessas outras a gente é obrigada a beber alguma coisa. Principalmente se tiver homem, porque eles pagam se estiverem com dinheiro. E tem que fazer striper também. Na Bacco não tem que fazer striper, mas na Enigma é obrigado (Entrevista, Prímula, novembro de 2015.

Em outro depoimento:

Têm homens que veem a mulher como bicho do mato. Se eles puderem fazer de tudo um pouco, eles fazem de ruim! Mas vai da mulher aceitar. Eles fazem o que a mulher aceitar, por exemplo, praticam o sexo anal. Nem toda mulher gosta! Eu pelo menos caio fora! Então, hoje, eu tenho os meus clientes fixos. Eu saio com os meus clientes fixos! O homem chega aqui e fala: - "Eu estou te notando, vamos sair?" Não, eu não saio! Eu tenho os meus clientes, a hora que eles quiserem sair, eles me ligam ou eles vêm aqui, me procuram. E se for homem estranho eu não saio. Justamente por isso, porque eu não tenho paciência, pois tenho receio de gerar uma discussão. Tem homem ignorante, por isso eu me sinto mais segura aqui (Entrevista, Gardênia, novembro de 2015).

Nesses espaços o programa acontecerá somente se houver um acordo prévio entre a prostituta e o cliente acerca do tempo, da modalidade dos serviços de natureza sexual a serem prestados e da remuneração estabelecida. Isso difere essa modalidade de prostituição daquele que ocorre em espaços fechados como, por exemplo, em boates, casas de massagem e clubes masculinos onde as trabalhadoras sexuais pagam diárias para os proprietários dos estabelecimentos. Além disso, elas não dispõem de autonomia em relação escolhas dos clientes, horários de trabalho, consumo de bebidas alcoólicas e multas por não comparecimento a casa, entre outras estratégias utilizadas para explorar o trabalho da prostituta.

\section{Considerações finais}

Uma contribuição central para esta investigação (levando-se em consideração a construção social das assimetrias de gênero), deve-se também ao estudo de Juliano (2005), particularmente o seu texto El trabajo sexual en la mira: polémicas y estereotipos. Nele, Juliano defende a legalização da prostituição como uma política que permitiria às mulheres 
que se prostituem o empoderamento necessário para enfrentar as dificuldades do trabalho sexual. Esta pesquisa estudo é a evidência de que a falta de regulamentação da prostituição incide significativamente no aumento da vulnerabilidade e do estigma que é imputado sobre as trabalhadoras sexuais, especialmente daquelas que se dedicam à prostituição de rua.

Os dados coligidos apontam que as prostitutas mantêm uma clientela fixa o que thes garante semanalmente uma remuneração mínima, bem como por questões de segurança como, por exemplo, estupros, furtos, violência física e simbólica, "calote do programa". Isso aponta para certo grau de autonomia dessas mulheres que, fazendo uso da sexualidade transgridem padrões da moral sexual, se inserem no trabalho sexual anulando os efeitos negativos da prostituição. Em suas práticas, elas estabelecem relações personalistas (com seus clientes e dono/as de estabelecimentos) onde parece haver margens seguras para a oferta de serviços de natureza sexual e negociação de seus agenciamentos corporais.

\section{Agradecimentos:}

O presente trabalho foi realizado com apoio da Coordenação de Aperfeiçoamento de Pessoal de Nível Superior - Brasil (CAPES) - Código de Financiamento 001.

\section{Referências}

ARAÚJO, Wagner dos Reis M. Tem barrageiro no brega? Um estudo acerca das trajetórias de mulheres que se prostituem nas áreas atingidas pelas Usinas Hidrelétricas Jirau e Santo Antônio no Estado de Rondônia. Porto Alegre, 2018. Tese (Doutorado em Sociologia) - Universidade Federal do Rio Grande do Sul.

ARAÚJO, Rogério. Prostituição: artes e manhas do ofício. Goiânia: Cânone Editorial. Ed. UCG, 2006.

BRUCKNER, Pascal; FILNKIELKRAUT, Alain. A nova desordem amorosa. São Paulo, Brasiliense, 1981.

FELDMAN, Bela. Desafios da Antropologia Brasileira. Brasília: (Org.). ABA Publicações, 2013.

GASPAR, Maria Dulce. Garotas de Programa: Prostituição em Copacabana e Identidade Social. Rio de Janeiro: Jorge Zahar Editor, 1985.

GOFFMAN, Erving. Estigma: notas sobre a manipulação da identidade deteriorada. Tradução de Márcia Bandeira de Mello Leite Nunes. - 4르 ed. [reimpr.]. - Rio de Janeiro: LTC, 2008.

JULIANO, Dolores. El trabajo sexual en la mira. Polémicas y estereótipos. In. Cadernos Pagu no. 25: Campinas July/Dec. 2005, pp. 79-106. 
KEMPADOO, Kamala. Mudando o debate sobre o tráfico de mulheres. In: Cad. Pagu No. 25, Campinas July/Dec. 2005, p. 55-78.

SILVA, Ana. P. e BLANCHETTE, Thaddeus. G. Amor um real por minuto: a prostituição como atividade econômica no Brasil urbano In: Sexualidade e política na América Latina: histórias, intersecções, paradoxos. ed. RJ : Sexual Policies Watch, 2011, v.1, p. 192-233.

SIMÕES, Soraya Silveira. Vila Mimosa: etnografia da cidade cenográfica da prostituição carioca. Niterói: EdUFF, 2010.

TEDESCO, Letícia. Explorando o negócio do sexo: uma etnografia sobre as relações afetivas e comerciais entre prostitutas e agenciadores em Porto Alegre. Dissertação de mestrado, UFRGS, 2008. 